\title{
PERCEPÇÕES SOBRE O COMPORTAMENTO DE INDISCIPLINA DE MENINAS E MENINOS NA ESCOLA
}

Luciano Campos da Silva

Edilaine Aparecida dos Santos PereiraII

I Universidade Federal de Ouro Preto (UFOP), Ouro Preto (MG), Brasil; lucianocampos@ufop.edu.br

II Universidade Federal de Ouro Preto (UFOP), Ouro Preto (MG), Brasil; edilaine.2010@yahoo.com.br

\section{Resumo}

O estudo investigou as percepções dos/as estudantes de uma escola pública de Belo Horizonte, estado de Minas Gerais, sobre a participação de meninas e meninos em episódios de indisciplina. Foram utilizados o Questionário Diagnóstico da Percepção de Indisciplina e Violência Segundo o Sexo dos/as Estudantes (Q-PIV), Quadro de Heteroclassificação e Autoclassificação de Comportamentos de Indisciplina (HAE) e entrevista semiestruturada. Participaram 167 estudantes do $8^{\circ}$ e $9^{\circ}$ anos do ensino fundamental. Os resultados indicam que é um equívoco pensar que as condutas de meninas e meninos na escola seguem um padrão rígido pautado apenas nas expectativas sociais de gênero, uma vez que verificamos uma multiplicidade de atitudes de meninas e meninos diante das regras escolares.

INDISCIPLINA ESCOLAR • DIFERENÇA DE GÊNERO • ENSINO FUNDAMENTAL

\section{PERCEPTIONS ABOUT THE UNDISCIPLINED BEHAVIOR OF GIRLS AND BOYS AT SCHOOL}

\section{Abstract}

This study investigated students' perceptions of the participation of girls and boys in episodes of lack of discipline, at a public school in Belo Horizonte, state of Minas Gerais. The Diagnostic Questionnaire of Perception of Violence and Lack of Discipline According to Students' Gender (Q-PIV), Table of Heteroclassification and Self-classification of Undisciplined Behavior (HAE) and semi-structured interview were used. 167 students from the 8th and 9th grades of elementary school participated. The results indicate that it is a mistake to think that the behaviors of girls and boys at school follow a strict pattern based only on social expectations of gender, since we found a multiplicity of attitudes of girls and boys towards school rules.

SCHOOL INDISCIPLINE • GENDER DIFFERENCE • ELEMENTARY EDUCATION 


\section{PERCEPCIONES SOBRE EL COMPORTAMIENTO DE INDISCIPLINA DE NIÑAS Y NIÑOS EN LA ESCUELA}

\section{Resumen}

El estudio investigó las percepciones de los estudiantes de una escuela pública en Belo Horizonte, estado de Minas Gerais, sobre la participación de niñas y niños en episodios de indisciplina. Fueron utilizados el Cuestionario Diagnóstico de La Percepción de indisciplina y violencia según el sexo de los estudiantes (Q-PIV), Cuadro de heteroclasificación y autoclasificación de comportamientos de indisciplina (HAE) y entrevista semiestructurada. Participaron 167 estudiantes de $8^{\circ}$ y $9^{\circ}$ años de primaria. Los resultados indican que es un error pensar que los comportamientos de niñas y niños en la escuela siguen un patrón rígido basado solo en las expectativas sociales de género, ya que verificamos una multiplicidad de actitudes de niñas y niños hacia las reglas escolares.

INDISCIPLINA ESCOLAR • DIFERENCIA DE GÉNERO • EDUCACIÓN PRIMARIA

\section{PERCEPTIONS CONCERNANT LE MANQUE DE DISCIPLINE DES GARÇONS ET DES FILLES À L'ÉCOLE}

\section{Résumé}

L'étude a examiné les perceptions des élèves d'un établissement de Belo Horizonte, dans l'État du Minas Gerais, concernant la paprticipation des filles et des garçons dans des épisodes d 'índiscipline. La collecte les données a été réalisée à l'aide d'un Questionnaire de Diagnostic de Perception de l'indiscipline et de Violence selon le genre des élèves (Q-PIV), d'une grille d'hétéro-classification et d'auto-classification des Comportements d'indiscipline (HAE) et d'un entretien semi-directif. 167 élèves de 6 e. et 5 e. au collège y ont participé. Les résultats indiquent qu'il est erroné de penser que le comportement scolaire des garçons et des filles suit un schéma rigide basé uniquement sur les attentes sociales de genre, puisque l'on a été vérifié qu'il y avait une multiplicité d'attitudes aussi bien des filles que des garçons à l'égard des normes scolaires.

INDISCIPLINE SCOLAIRE • DIFFÉRENCE DE GENRE・ENSEIGNEMENT PRIMAIRE 
central para se compreenderem as desigualdades educacionais, especialmente no contexto brasileiro (Silva \& Matos, 2017). Como atestam frequentemente estudos internacionais como o Programa Internacional de Avaliação de Estudantes (Pisa) (Organisation for Economic Co-operation and Development [OCDE], 2011, 2013) e a Pesquisa Internacional sobre Ensino e Aprendizagem (Teaching and Learning International Survey [Talis]) (OECD, 2014), no Brasil, a indisciplina escolar encontra-se frequentemente associada ao desempenho acadêmico dos/as estudantes, sendo que o país se situa entre as nações nas quais a presença de comportamentos de indisciplina nas escolas assume um caráter mais marcante.

Embora seja um tema de grande relevância, ainda não dispomos, no Brasil, de uma produção considerável de pesquisas que elegem a indisciplina como objeto específico de análise. Um levantamento bibliográfico recentemente realizado por Aquino (2016) indica que a indisciplina, mesmo sendo uma das principais queixas presentes no discurso dos/as profissionais da educação, ainda é pouco estudada, e somente na última década é possível detectar um crescimento mais considerável do interesse da comunidade científica em estudar o fenômeno.

No que diz respeito à explicação do fenômeno, a literatura acadêmica tem sido unânime em indicar que a indisciplina é um fenômeno complexo, cuja investigação deve considerar a existência de uma multiplicidade de fatores. Silva (2007), por exemplo, entende que os comportamentos de indisciplina dos/as estudantes só poderiam ser devidamente compreendidos por meio do cruzamento de diversos fatores sociais, familiares, escolares, pedagógicos e relacionais que se conjugam como "condições de possibilidade" para sua ocorrência.

Em que pese a necessidade de se compreender a multiplicidade dos fatores relacionados ao fenômeno, um aspecto ainda pouco explorado pela literatura acadêmica tem sido a relação entre a indisciplina e a questão do gênero e/ou sexo dos/as estudantes. ${ }^{1} \mathrm{O}$ termo gênero se refere à construção social e histórica dos conceitos de masculinidade e de feminilidade produzidos a partir das características e diferenças biológicas, anatômicas e sexuais de homens e mulheres (Scott, 1990). Desse modo, como ressaltam Moreira e Santos (2002), estudam-se o gênero na escola e a indisciplina na escola, mas sem buscar inter-relacionar ambos os fenômenos. Ainda mais ausentes são os estudos que tomam como objeto específico de análise a indisciplina praticada pelas meninas nas escolas. De modo geral, no imaginário social, acadêmico e escolar, a indisciplina tem sido frequentemente considerada uma prática social quase exclusiva dos meninos, sendo pouca atenção conferida à indisciplina praticada pelas meninas. Poucos estudos buscam investigar, por exemplo, a forma e a frequência da participação das meninas nos comportamentos de indisciplina, ou as explicações dadas pelos/as alunos/as e professores/as para essa participação (Moreira \& Santos, 2002; Neves, 2008; Prodócimo et al., 2010; Santos, 2007; Vargas, 2008).

Nesse sentido, este trabalho tem como objetivo contribuir para o preenchimento dessa importante lacuna no campo investigativo, ao apresentar os resultados de uma investigação que buscou analisar as percepções dos/as estudantes de uma escola pública de Belo Horizonte, estado de Minas Gerais (MG), sobre a participação de meninas e de meninos em episódios de indisciplina no ambiente de sala de aula. Como alerta Carvalho (2007, p. 20), “. . . no Brasil conhecemos muito 
pouco sobre as opiniões das próprias crianças quanto ao ser menino ou menina e, também, quanto ao ser bom aluno; ou suas percepções sobre as masculinidades e feminilidades frente às regras disciplinares da escola”. O conhecimento dessas percepções torna-se bastante relevante, especialmente em um momento em que alguns estudos têm enfatizado que, na percepção dos/as professores/as, a conduta das meninas diante das regras escolares estaria se alterando, uma vez que elas tenderiam a protagonizar tanto quanto os meninos os atos de indisciplina (Moreira \& Santos, 2002; Neves, 2008; Prodócimo et al., 2010; Santos, 2007; Vargas, 2008). Ressaltamos, ainda, que nos raros estudos que abordam essa relação entre indisciplina e gênero, as análises são frequentemente realizadas a partir das percepções dos/as professores/as, sendo mais escassos os estudos cujas análises partam das percepções que têm os/as próprios/as estudantes sobre seus comportamentos escolares.

De modo específico, com base nas percepções dos/as estudantes, o estudo buscou responder às seguintes questões: De que forma os/as estudantes percebem a frequência e a forma de participação de meninas e de meninos nos episódios de indisciplina? Quais tipos de indisciplina seriam, na percepção dos/as estudantes, mais frequentemente praticados por meninas e por meninos? Quais explicações os/as estudantes conferem às semelhanças ou diferenças observadas no comportamento disciplinar de meninas e meninos?

Destacamos que estudar as percepções dos/as estudantes sobre indisciplina e violência torna-se importante na medida em que a existência do fenômeno e a sensação ou opinião que se tem sobre sua presença nas escolas são ambos elementos sociológicos relevantes. Como lembra Dubet (2011, p. 295), “. . . no que se refere à socialização as representações e as crenças são tão importantes quanto os fatos ou, mais precisamente, que elas são fatos simbólicos dotados de uma eficácia própria”. Ademais, metodologicamente, além de viável, essa estratégia tem se mostrado eficaz e apropriada à investigação de fenômenos educacionais, especialmente de fenômenos interativos em sala de aula, conforme indica a literatura (Matos, 2006; Sortkaer \& Reimer, 2016).

\section{Escola, gênero e indisciplina}

Ao analisarmos a literatura, é possível afirmar que a abordagem acadêmica da relação entre indisciplina e gênero no Brasil esteve inicialmente associada à tentativa de se compreender o desempenho acadêmico diferenciado entre meninas e meninos na escola, temática que à época já contava com alguma tradição, especialmente em países como os Estados Unidos, a Inglaterra, a França e o Canadá (Carvalho, 2003).

Nesse sentido, os trabalhos pioneiros desenvolvidos por Brito (2004), Carvalho (2001, 2003, 2004a, 2007), Matos e Vasconcelos (2015), Rodrigues (2009) e Silva et al. (1999), entre outros, que buscavam compreender os mecanismos escolares que contribuíam para o fracasso escolar preponderante dos meninos, acabaram por abrir o caminho para uma discussão mais específica sobre a relação que meninas e meninos mantinham com as regras escolares e sobre o modo como essa relação seria influenciada por estereótipos de gênero presentes na sociedade, na escola e entre os/as professores/as.

Em um levantamento das dissertações e teses brasileiras que se dedicaram a examinar essa diferença de desempenho, Carvalho (2012) afirma que é possível identificar, a partir dos estudos, a existência de certa homogeneidade na cultura escolar, em especial nos anos iniciais do ensino fundamental, no que tange a vários aspectos: a) os/as professores/as tendem a atribuir ao comportamento indisciplinado a principal razão para as dificuldades escolares dos meninos; b) os/as professores/as atribuem principalmente às famílias a origem de problemas de indisciplina entre os estudantes, como se a escola fosse neutra no processo de construção de masculinidades 
e feminilidades; c) nem sempre os/as autores/as dos estudos conseguiram distanciar-se criticamente das opiniões e estereótipos produzidos pelos/as professores/as investigados/as, pautados geralmente pela polaridade e pela hierarquia entre masculino e feminino. Quando foram capazes de superá-los, conseguiram perceber a permanente ruptura, a convivência dos contrários e a necessidade de diversificar feminino e masculino, intersectando-os com diferenças de classe, raça, culturas locais, o que faz multiplicar as percepções sobre as formas de ser menina e menino no ambiente escolar.

Mais recentemente, porém, temos assistido ao desenvolvimento de uma produção acadêmica que aborda essa relação entre indisciplina e gênero como um objeto específico de análise. São trabalhos que têm procurado analisar o comportamento disciplinar das meninas, focando na análise das transgressões por elas realizadas no interior dos estabelecimentos de ensino. De modo geral, é possível afirmar que esse interesse acadêmico pela temática deriva basicamente de duas constatações: 1) seria frágil o vínculo determinista estabelecido entre indisciplina e masculinidade, reprodutor de estereótipos de gênero, que conduziria à percepção generalizada de que as meninas não transgridem as regras escolares; 2) existiria nas escolas uma crescente percepção de que o comportamento das meninas estaria sofrendo mudanças nos últimos anos e que, grosso modo, elas estariam passando de expectadoras a protagonistas da indisciplina.

Nesse conjunto de estudos, situam-se investigações como, por exemplo, as realizadas por Moreira e Santos (2002), Vargas (2008), Neves (2008), Prodócimo (2010) e Santos (2007). Seria impossível fazer um relato detalhado e completo desses estudos no âmbito de um artigo. Entretanto, vale a pena destacar dois desses trabalhos no intuito de situar os tipos de conclusões que já tem sido possível extrair a partir dos resultados dessas investigações.

O primeiro exemplo de estudo sobre a temática é o desenvolvido por Moreira e Santos (2002) e que se intitula Indisciplina na escola: uma questão de gênero? Nele as autoras problematizam a inter-relação entre indisciplina e gênero e analisam as sanções disciplinares aplicadas às meninas e aos meninos nas escolas. Para elas, essa problematização é importante, pois ajuda a compreender como as práticas normatizadoras e as sanções disciplinares podem convergir para a produção e a definição de determinados padrões de comportamento como especificamente masculinos ou femininos. Para realização da pesquisa, as autoras buscaram analisar as atitudes que eram consideradas indisciplinadas em alunas e alunos do $9^{\circ}$ ano de uma escola estadual do município de Presidente Prudente, estado de São Paulo. Para isso, utilizaram instrumentos diversificados de pesquisa, como observações, entrevistas e análise do livro de ocorrências. ${ }^{2}$

Como resultados, as autoras verificaram que a escola tende a reproduzir as desigualdades fundadas nas diferenças de gênero. A instituição realiza suas práticas fundamentadas em padrões hegemônicos de feminilidade e de masculinidade, gerando tratamentos diferenciados diante dos comportamentos dos/as estudantes. Uma dessas práticas foi verificada nos registros do livro de ocorrências, no qual as autoras constataram o tratamento diferenciado conferido pela escola às meninas quando eram aplicadas a elas algum tipo de sanção. Verificaram que, diante de um mesmo comportamento, as meninas tendiam a ser mais severamente punidas que os meninos, uma vez que se esperavam, mais delas do que dos meninos, atitudes como obediência e compromisso, atributos considerados eminentemente femininos.

Vale destacar que esse tipo de desproporcionalidade na aplicação das sanções escolares tem sido amplamente estudado, por exemplo, nos Estados Unidos, país no qual sanções como a expulsão e a suspensão dos/as estudantes são geralmente permitidas, originando informações quantitativas 
precisas sobre os indivíduos que delas são os alvos mais frequentes. A título de exemplo, pode ser citado o relatório Exclusionary school discipline: An issue brief and review of the literature, ${ }^{3}$ conduzido por Danfeng Soto-Vigil Koon (2013), que indicou que estudantes negras e negros eram mais propensos/as do que outros/as estudantes a ser suspensos em decorrência de infrações disciplinares e a receber punições graves, como suspensão da escola. Outro exemplo é o trabalho Girls behaving badly? Race, gender, and subjective evaluation in the discipline of African American girls, ${ }^{4}$ desenvolvido por Morris e Perry (2017), no qual se verifica que os alunos negros eram mais propensos a ser punidos do que os estudantes brancos e que as meninas negras eram muito mais prováveis do que outras meninas de ser citadas por infrações, comportamentos disruptivos e comportamentos agressivos. Nos dois casos, essa desproporcionalidade seria explicada pelas expectativas e estereótipos negativos que se reproduzem na escola em torno das crianças negras e, em especial, das meninas negras.

Moreira e Santos (2002) perceberam, também, que os/as docentes, em sua maioria, atribuem a indisciplina das meninas às questões relacionadas à sexualidade, enfatizando que elas geralmente ficariam em grupos falando sobre namoros e que seriam muito "assanhadas", isto é, gostariam de se exibir para os/as outros/as e, para isso, tenderiam a fazer uso do apelo sexual. Ou seja, a escola acabaria reforçando os estereótipos de gênero, exigindo mais das meninas atitudes como o silêncio, a dedicação aos estudos e a disciplina e, especialmente, demandaria delas que adiassem sua sexualidade e que tivessem, na escola, um comportamento assexuado. Desse modo, as meninas seriam duplamente questionadas diante da transgressão das regras escolares, num processo bastante similar ao que os estudos sobre criminalidade feminina têm definido como condenação por dupla desviança. ${ }^{5} \mathrm{Ou}$ seja, as meninas seriam mais severamente punidas porque desviariam duplamente, transgredindo as regras da escola e também as expectativas sociais de gênero. Dessa forma, Moreira e Santos (2002) chamam a atenção para a construção de perfis de feminilidade e de masculinidade na escola, compreendendo essa instituição como uma das dimensões sociais responsáveis pela produção e reprodução das desigualdades fundadas nas diferenças de gênero.

Outro exemplo de trabalho brasileiro sobre o tema foi o desenvolvido por Neves (2008) em sua dissertação de mestrado - As meninas de agora estão piores do que os meninos: gênero, conflito e violência na escola. A pesquisa teve como ponto de partida o discurso de que haveria mudanças significativas no comportamento das meninas no ambiente escolar e de que as meninas estariam piores que os meninos no que tange à disciplina. $\mathrm{O}$ estudo foi realizado em uma escola da rede estadual situada na zona norte do município de São Paulo e teve como objeto central de análise o comportamento de algumas meninas do ensino fundamental II consideradas violentas por seus/suas professores/as. Para realização da investigação empírica foram empregados diversos instrumentos de coleta de dados como observações, questionários, reuniões com grupos de alunas e entrevistas semiestruturadas.

Entre os diversos resultados da pesquisa, constatou-se que, de fato, as meninas investigadas tinham como prática condutas violentas no interior da escola. Já os meninos, mesmo aqueles considerados indisciplinados, tenderiam a buscar mais o diálogo como forma de resolver seus conflitos, na medida em que pareciam perceber que a taxa de letalidade seria maior entre eles quando entravam em confronto. Contudo, o estudo constatou que as brigas envolvendo as meninas não eram geralmente motivadas por questões relacionadas ao envolvimento afetivo com os rapazes, como frequentemente divulgado na escola. As brigas surgiam geralmente como forma de reestabelecer a reputação perdida ou de romper com certa invisibilidade de gênero presente na escola.

\footnotetext{
Tradução: Disciplina escolar excludente: uma breve edição e revisão da literatura.

Tradução: Meninas se comportando mal? Raça, gênero e avaliação subjetiva da disciplina de meninas afro-americanas.

Por exemplo, Matos e Machado (2012).
} 
Essa restauração ocorria, por exemplo, no caso das fofocas na escola, das quais as meninas eram sempre as vítimas prioritárias. As fofocas teriam o poder de provocar tensões ao exporem a vida íntima das estudantes e contestarem publicamente suas reputações, especialmente na esfera sexual e dos relacionamentos afetivos. As autoras destacam que seria especialmente no ambiente doméstico e escolar que as jovens desenvolveriam essa prática do uso da violência como forma de estabelecimento e restauração da ordem, da individualidade e da dignidade. Para isso, utilizavam como recurso as mesmas práticas observadas em casa nas atitudes de seus pais: agredir com o uso de força ou de palavras de baixo calão. Destacam, ainda, que as brigas cu mpriam o papel de romper com certa invisibilidade de gênero presente na escola e que, nesse sentido, essas meninas aprenderiam com os rapazes como alcançar a popularidade e o reconhecimento nas escolas: envolverem-se nas brigas que sempre contavam com um público grande e cativo.

Por fim, o autor conclui que as agressões praticadas pelas garotas no ambiente escolar desafiariam a tarefa histórica da escola de educar as novas gerações, mas, ao mesmo tempo, funcionariam como modo de resistência aos estereótipos de gênero que insistem em definir as meninas como frágeis, pacíficas e incapazes de transgredir. Salienta-se, porém, que essas agressões acabariam reproduzindo parte desses estereótipos que compõem a hegemonia masculina ao reforçarem a ideia de que a violência seria a melhor forma de resolução dos conflitos.

Desse modo, os resultados desses e de outros estudos nos conduzem à conclusão de que, em que pese a persistência de certas imagens construídas em torno do comportamento das meninas na escola e na sociedade, parece haver uma parcela das meninas que transgride os estereótipos de gênero pautados na submissão, na docilidade, na fragilidade, atributos "ordenados" para elas. Dessa forma, poder-se-ia aventar a hipótese de que existe um movimento de contestação de padrões de gênero entre as meninas, especialmente por parte dessas meninas transgressoras, objetivando se fazerem visíveis no espaço escolar e social. Não é possível dizer que se trata de um movimento político, intencional e organizado, mas um movimento cotidiano de mudanças de paradigmas em relação aos papéis sociais de gênero. Nesse sentido, destacamos, neste trabalho, a relevância de se investigarem as percepções que os/as estudantes apresentam acerca da participação de meninas e meninos nos episódios de indisciplina e violência na escola. Com a realização deste estudo, esperamos contribuir para o debate sobre a interface indisciplina e gênero, ainda pouco explorada no meio acadêmico. Enfatizamos que o que nos move mais especificamente são as percepções que os/as estudantes têm da conduta disciplinar das meninas. Porém, por ser gênero um conceito relacional e tendo em vista a necessidade científica da comparação, os dados referentes às meninas foram produzidos e analisados comparativamente aos dos meninos (Scott, 1990). Foi buscando, portanto, cumprir esse objetivo de captar as percepções dos/as estudantes sobre a indisciplina protagonizada pelas meninas que realizamos uma pesquisa que buscou conciliar a abordagem qualitativa e quantitativa, mesclando, assim, diferentes instrumentos para a coleta de dados. É o que passaremos a apresentar na seção dedicada ao percurso metodológico da pesquisa.

\section{O percurso metodológico da pesquisa}

A escola selecionada para realização da pesquisa localiza-se em uma região periférica na cidade de Belo Horizonte (MG), área que abarca os contrastes sociais, isto é, setores desfavorecidos e setores médios/intelectualizados dos estratos sociais. A escola era de médio porte e tinha 550 estudantes matriculados do $1^{\circ}$ ao $9^{\circ}$ ano do ensino fundamental em 2018. No total, 167 estudantes matriculados nas turmas de $8^{\circ}$ e $9^{\circ}$ anos responderam aos instrumentos quantitativos 
da pesquisa e 24 participaram das entrevistas. ${ }^{6} \mathrm{~A}$ opção por trabalhar com estudantes do $8^{\circ} \mathrm{e}$ $9^{\circ}$ anos se deu pelo fato de as pesquisas nacionais e internacionais indicarem ser nessa fase que as escolas se deparariam com maiores problemas de indisciplina (Estrela, 1992; Silva, 2007). Dos 167 estudantes matriculados em 2018, ano de realização da pesquisa, 90 (53,9\%) são do sexo feminino e 77 (46,1\%) do sexo masculino. Quanto à idade, 58 (35\%) tinham 13 anos, 68 (41\%) tinham 14, 15 (9\%) tinham 15, 4 (2\%) tinham 16, 2 (1\%) tinham 17 anos e 20 (12\%) estudantes não souberam ou não quiseram responder. Quanto à raça/cor, 41 (25\%) se autodeclaram brancos, 19 (11\%) pretos, 70 (42\%) pardos, 7 (4\%) indígenas, 7 (4\%) amarelos e 23 (14\%) não responderam à questão referente à cor ou raça.

Neste estudo, as percepções dos estudantes foram analisadas a partir da conjugação de dados qualitativos e quantitativos, visando a ampliar e triangular as informações disponíveis (Bruggemann \& Parpinelli, 2008). Assim, foram empregados os seguintes instrumentos de coleta de dados:

\section{Questionário Diagnóstico da Percepção de Indisciplina e Violência Segundo o Sexo dos/as Estudantes (Q-PIV)}

Para apurar as percepções dos/as estudantes acerca da participação de meninas e meninos nos mais variados tipos de comportamentos de indisciplina escolar, fizemos a adaptação de um questionário construído por Silva e Matos (2016) que teve como objetivo diagnosticar os comportamentos de indisciplina e de violência escolar na Região dos Inconfidentes, Minas Gerais. A construção do questionário pelos autores foi inspirada no modelo apresentado por Pasquali (1999). $\mathrm{O}$ instrumento adaptado deu origem ao Q-PIV, formado por 41 itens, cujas opções de respostas são dadas pela escala Likert, escala de medida psicométrica muito utilizada nas pesquisas por possibilitar que o/a pesquisado/a expresse com detalhes sua opinião sobre a frequência de atitudes, fatos e sentimentos. Nesta pesquisa, a escala Likert propicia captar a frequência com que, na percepção dos/as estudantes, os comportamentos de indisciplina e de violência são manifestados em sala de aula por meninas e meninos, utilizando cinco níveis de respostas distintas: nunca, raramente, frequentemente, sempre e não sei. $\mathrm{O}$ questionário foi dividido em três partes ou seções: na primeira, o/a estudante responde sobre suas características socioculturais - idade, sexo, cor/raça, formação familiar, escolaridade e profissão dos pais -; na segunda, responde questões referentes à participação de meninas e meninos em 14 diferentes tipos de episódios de indisciplina, tendo em vista, especialmente, classificações que vêm sendo realizadas pela literatura acadêmica (Silva \& Matos, 2016); na terceira e última seção, o estudante reponde a 16 questões referentes à participação de meninas e meninos em diferentes episódios de violência escolar, novamente tendo em vista algumas classificações desse fenômeno difundidas pela literatura acadêmica (Silva \& Matos, 2016). Neste artigo serão analisadas apenas as questões relativas aos comportamentos de indisciplina.

Nota-se que, no âmbito desta pesquisa, indisciplina e violência são considerados fenômenos diferentes, em que pese o fato de nem sempre ser possível fazer uma distinção conceitual precisa entre eles (Silva \& Nogueira, 2008). Assim, consideramos a indisciplina escolar um fenômeno interativo e relacional que se concretiza pelo não cumprimento das regras que presidem, orientam e estabelecem as condições de funcionamento das atividades pedagógicas na escola e nas salas de aula (Amado, 2001; Silva, 2007).

Para analisar as informações coletadas, criou-se um banco de dados no software Statistical Package for Social Sciences (SPSS) versão 10.

6 Participaram da pesquisa nove estudantes surdos/as. A participação na pesquisa demandou a presença de um tradutor/ intérprete de libras/língua portuguesa. 


\section{Quadro de Heteroclassificação e Autoclassificação dos/as Estudantes Segundo o Comportamento Disciplinar em Sala de Aula (Q-HAE)}

O Q-HAE foi elaborado com objetivo de verificar a forma como os/as estudantes se percebiam e tendiam a perceber os/as seus/suas colegas de sala de aula, tanto as meninas quanto os meninos, noque tangeà frequência desuas participações nos episódios deindisciplina. Oinstrumento foi inspirado na classificação dos/as estudantes feita por Silva (2007), que levou em consideração a frequência com que os/as estudantes participavam dos episódios de indisciplina nas salas de aula investigadas pelo autor. Em seu trabalho, Silva (2007) elaborou uma classificação dos/as estudantes em três tipos: 1) os frequentes na disciplina; 2) os frequentes na indisciplina; e 3) os ocasionais na indisciplina. A saber, os/as estudantes "frequentes na disciplina” são aqueles/as que tendem a apresentar uma conduta bastante regular de obediência às regras escolares. Já os/as estudantes "frequentes na indisciplina" são aqueles/as que apresentam maior regularidade no envolvimento em eventos tidos, pelos/as docentes, como de indisciplina. Por fim, os/as alunos "ocasionais na indisciplina” são aqueles que só se envolveriam em comportamentos de indisciplina de forma esporádica, uma vez que seus comportamentos oscilam bastante ao longo da jornada escolar. É importante ressaltar que, ao utilizar a ideia de frequência, o autor visa a superar o binarismo disciplinado-indisciplinado, bastante comum no meio escolar. A frequência é compreendida, assim, como forma de não essencializar os sujeitos e suas condutas, visto que, no contexto concreto, o comportamento dos/as alunos tende a assumir determinados padrões, mas nunca podem ser considerados estáticos e imutáveis. Nesse sentido, o uso de expressões como "disciplinado" ou "indisciplinado" para classificar os estudantes, comum no ambiente escolar, tende a criar estigmas ou a não dar conta da complexidade e plasticidade do comportamento dos alunos diante das regras escolares (Silva, 2007).

Partindo dessa categorização realizada por Silva (2007), o Q-HAE foi construído da seguinte forma: para cada turma, organizou-se uma listagem com o nome de todos/as os/as estudantes. Nessa listagem, eles/elas deveriam fazer uma classificação de si próprios (autoclassificação) e uma classificação de todos/as os/as seus/suas colegas (heteroclassificação) relativamente à frequência de suas participações nos episódios de indisciplina que ocorriam em sala de aula. Portanto, para cada um dos nomes da lista, incluindo seu próprio nome, os/as estudantes sinalizaram em qual categoria cada pessoa da listagem se enquadrava: se frequente na disciplina, frequente na indisciplina ou ocasional na indisciplina. Essa tipologia foi explicada de forma simplificada a cada estudante antes do preenchimento do quadro. Uma das vantagens do Q-HAE é que podemos obter uma avaliação da conduta de cada estudante baseada na percepção de um conjunto amplo de pessoas com as quais ele/ela convive quotidianamente e não exclusivamente a partir da avaliação de seus/suas professores/as. No contexto desta pesquisa, coletaram-se 167 quadros, sendo realizadas 167 heteroclassificações e 152 autoclassificações. Essa diferença entre o número de autoclassificados/as e de heteroclassificados/as ocorreu devido à ausência de 15 estudantes no dia da aplicação do instrumento.

Para realizar a análise dos dados obtidos com a aplicação do Q-HAE, no banco de dados criado no SPSS, inseriram-se três variáveis com objetivo de identificar o modo como cada estudante foi classificado/a por seus pares e como ele/ela próprio/a se autoclassificou: 1) uma variável que indicava a autoclassificação feita por cada estudante; 2) uma variável que identificava a heteroclassificação de cada estudante, considerando-se a tipologia para a qual recebeu o maior número de heteroclassificações; e 3) uma variável relativa à coincidência ou não entre a autoclassificação e a heteroclassificação de cada estudante. 


\section{As entrevistas semiestruturadas}

Com objetivo de aprofundar as análises, realizaram-se entrevistas semiestruturadas com os/as estudantes baseadas em um roteiro previamente elaborado, a partir do qual se estimulava o/a entrevistado/a discorrer sobre questóes relacionadas aos objetivos da pesquisa. Foram selecionados/as 24 estudantes. Para isso, buscamos equilibrar a participação de meninas e meninos e também as características dos/as estudantes em face da heteroclassificação que receberam de seus/suas colegas no Q-HAE, conforme Tabela 1.

\section{TABELA 1}

Gênero e heteroclassificação dos/as entrevistados/as $(n=24)$

\begin{tabular}{c|c|c|c}
\hline Gênero/sexo & $\begin{array}{c}\text { Frequente na disciplina } \\
(\mathrm{n})\end{array}$ & $\begin{array}{c}\text { Ocasional na indisciplina } \\
(\mathrm{n})\end{array}$ & $\begin{array}{c}\text { Frequente na indisciplina } \\
(\mathrm{n})\end{array}$ \\
\hline Meninas & 5 & 5 & 2 \\
\hline Meninos & 4 & 4 & 4 \\
\hline
\end{tabular}

Fonte: Elaboração dos autores a partir dos dados do Q-HAE.

As entrevistas foram realizadas e gravadas no laboratório de informática da escola e posteriormente transcritas. As análises foram realizadas segundo a técnica de análise de conteúdo (Bardin, 2011).

\section{Resultados e discussão}

\section{Os comportamentos de indisciplina de meninas e meninos}

A seguir, analisaremos os dados obtidos por meio do Q-PIV. A Tabela 2 apresenta as percepções dos/as estudantes acerca da frequência com que os diferentes tipos de comportamentos de indisciplina seriam protagonizados por meninas e meninos nas turmas investigadas.

TABELA 2

Percepções sobre a frequência com que meninas e meninos protagonizam comportamentos de indisciplina em sala de aula $(n=167)$

\begin{tabular}{|c|c|c|c|c|c|c|}
\hline Comportamento & Gênero & $\begin{array}{c}N \\
(\%) \\
\end{array}$ & $\begin{array}{c}\mathrm{R} \\
(\%) \\
\end{array}$ & $\begin{array}{c}F \\
(\%) \\
\end{array}$ & $\begin{array}{c}S \\
(\%)\end{array}$ & $\begin{array}{l}\text { NS } \\
(\%)\end{array}$ \\
\hline \multirow{2}{*}{ Fazer barulho e desordem em sala } & Meninas & 4,8 & 19,7 & 50,3 & 19,0 & 6,1 \\
\hline & Meninos & 1,4 & 12,2 & 44,2 & 34,0 & 8,2 \\
\hline \multirow{2}{*}{ Conversar em sala de aula } & Meninas & 1,4 & 18,4 & 46,3 & 25,9 & 8,2 \\
\hline & Meninos & 0,0 & 10,9 & 51,0 & 32,7 & 5,4 \\
\hline \multirow{2}{*}{ Circular pela sala } & Meninas & 5,4 & 39,5 & 37,4 & 10,2 & 7,5 \\
\hline & Meninos & 2,7 & 29,3 & 42,9 & 19,0 & 6,1 \\
\hline \multirow{2}{*}{ Sair de sala sem a permissão do/a professor/a } & Meninas & 32,7 & 47,6 & 8,2 & 4,8 & 6,8 \\
\hline & Meninos & 23,8 & 39,5 & 19,7 & 9,5 & 7,5 \\
\hline \multirow{2}{*}{ Chegar atrasados/as em sala } & Meninas & 8,2 & 43,5 & 34,0 & 8,2 & 6,1 \\
\hline & Meninos & 4,1 & 41,5 & 32,0 & 14,3 & 8,2 \\
\hline \multirow{2}{*}{ "Matar" aula } & Meninas & 52,7 & 21,2 & 2,7 & 0,7 & 22,6 \\
\hline & Meninos & 45,6 & 23,1 & 7,5 & 0,0 & 23,8 \\
\hline
\end{tabular}




\begin{tabular}{|c|c|c|c|c|c|c|}
\hline Comportamento & Gênero & $\begin{array}{c}N \\
(\%)\end{array}$ & $\begin{array}{c}\mathrm{R} \\
(\%)\end{array}$ & $\begin{array}{l}F \\
(\%)\end{array}$ & $\begin{array}{c}S \\
(\%)\end{array}$ & $\begin{array}{l}\text { NS } \\
(\%)\end{array}$ \\
\hline \multirow{2}{*}{$\begin{array}{c}\text { Distrair-se com objetos (celular, jogos, brinquedos, } \\
\text { fones de ouvido, etc.) }\end{array}$} & Meninas & 9,5 & 29,3 & 31,3 & 23,1 & 6,8 \\
\hline & Meninos & 4,1 & 21,1 & 40,8 & 30,6 & 3,4 \\
\hline \multirow{2}{*}{ Não realizar as atividades indicadas } & Meninas & 0,7 & 9,5 & 49,0 & 32,0 & 8,8 \\
\hline & Meninos & 0,7 & 11,6 & 51,0 & 28,6 & 8,2 \\
\hline \multirow{2}{*}{ Dedicar-se às atividades de outros/as professores/as } & Meninas & 9,5 & 34,7 & 30,6 & 10,9 & 14,3 \\
\hline & Meninos & 7,5 & 29,3 & 36,7 & 10,9 & 15,6 \\
\hline \multirow{2}{*}{$\begin{array}{l}\text { Fazer brincadeiras, gozações ou debochar dos/as } \\
\text { colegas }\end{array}$} & Meninas & 12,2 & 32,0 & 25,2 & 19,7 & 10,9 \\
\hline & Meninos & 6,1 & 19,7 & 30,6 & 37,4 & 6,1 \\
\hline \multirow{2}{*}{$\begin{array}{l}\text { Discutir verbalmente ou falar palavrões com os/as } \\
\text { colegas }\end{array}$} & Meninas & 10,2 & 29,9 & 26,5 & 27,2 & 6,1 \\
\hline & Meninos & 7,5 & 21,1 & 27,9 & 38,1 & 5,4 \\
\hline \multirow{2}{*}{ Desobedecer às ordens do/a professor/a? } & Meninas & 17,7 & 41,5 & 21,1 & 4,8 & 15,0 \\
\hline & Meninos & 10,2 & 32,7 & 30,6 & 13,6 & 12,9 \\
\hline \multirow{2}{*}{ Responder de forma mal-educada ao/à professor/a } & Meninas & 22,4 & 42,2 & 16,3 & 2,7 & 16,3 \\
\hline & Meninos & 16,3 & 38,1 & 23,8 & 10,2 & 11,6 \\
\hline \multirow{2}{*}{$\begin{array}{c}\text { Fazer brincadeiras, gozações ou debochar do/a } \\
\text { professor/a }\end{array}$} & Meninas & 38,4 & 26,7 & 11,0 & 2,7 & 21,2 \\
\hline & Meninos & 29,9 & 25,9 & 14,3 & 8,8 & 21,1 \\
\hline
\end{tabular}

Fonte: Elaboração dos autores a partir dos dados do Q-PIV.

$\mathrm{F}=$ frequentemente; $\mathrm{N}=$ nunca; $\mathrm{NS}=$ não sei; $\mathrm{R}=$ raramente; $\mathrm{S}=$ sempre.

Algumas conclusões podem ser extraídas a partir da análise dos dados apresentados na Tabela 2.

Primeiramente, as percepções dos estudantes parecem confirmar os resultados de diferentes estudos nacionais e internacionais que indicam que os comportamentos de indisciplina seriam bastante frequentes em sala de aula (OCDE, 2011, 2013; Silva \& Matos, 2014, 2017). Nota-se que, para a ampla maioria dos comportamentos inventariados, a frequência de respostas "frequentemente" e "sempre" somadas é superior a 50\%, seja para meninas ou meninos, sendo que, em alguns casos, ultrapassa a casa dos $70 \%$. As maiores frequências, quando consideradas as respostas "frequentemente" e "sempre", seja para meninas ou meninos, foram encontradas para os seguintes comportamentos: não realizar as atividades (81 e 79,6\%), conversar em sala de aula (72 e 83,7\%), fazer barulho $(69,3$ e $78,2 \%)$ e distrair-se com objetos $(54,4$ e $71,4 \%)$. São comportamentos que, conforme Amado (2001), tendem a atingir mais imediatamente o processo-aula, isto é, impedem ou perturbam o bom funcionamento das aulas ao interferirem no processo de ensino e na organização e gestão da sala de aula. Frequências menos elevadas, quando considerado o conjunto de respostas "frequentemente" e "sempre", seja para meninas ou meninos, foram encontradas para os seguintes comportamentos: circular pela sala (47,6 e 61,9\%), chegar atrasado em sala $(42,2$ e 46,3\%), dedicar-se a atividades de outros professores $(41,5$ e 47,6\%), fazer brincadeiras, gozações ou debochar dos colegas (44,9 e 68\%) e discutir verbalmente ou falar palavrões com colegas (53,7 e 66\%). Aqui, novamente, aparecem alguns comportamentos que atingem o processo-aula e outros que, conforme Amado (2001), se associam com as relações interpessoais, no caso as relações entre os/as próprios/as alunos/as. Já as menores frequências, quando considerado o conjunto de respostas "frequentemente" e "sempre", seja para meninas ou meninos, foram encontradas para comportamentos como: sair de sala sem permissão ( 13 e 29,2\%), matar aula $(3,4$ e $7,5 \%)$, desobedecer às ordens dos professores $(25,9$ e 44,2\%), responder de forma 
mal-educada aos professores (19 e 34\%) e fazer gozações ou brincadeiras com os professores (13,7 e 23,1\%). A maioria é comportamento de indisciplina que atinge mais diretamente a relação entre professor e aluno. Dessa forma, embora seja correto dizer que qualquer comportamento de indisciplina questione, de algum modo, a autoridade do professor, aqueles que fazem isso de forma mais aberta seriam, nas percepções dos estudantes, mais raros nas turmas investigadas. Poder-se-ia dizer que se, por um lado, nossos dados confirmam que a autoridade do professor tem sido de fato permanentemente questionada nas escolas pela presença marcante de atos de indisciplina, essa, contudo, não é tão frequentemente questionada de forma direta por meio do confronto permanente e aberto com a figura do professor. Ou seja, pelos dados do Q-PIV, ao contrário do que faz crer certo imaginário social sobre a profissão docente, é possível inferir que os/as estudantes investigados/as tendem a manter algum nível de reconhecimento da autoridade do professor em sala de aula. Em seu conjunto, esses dados indicam que, conforme Silva e Matos (2017), a indisciplina parece de fato ter se tornado um fenômeno bastante comum e generalizado no ambiente escolar. Não por acaso, a literatura acadêmica indica que ela tende a se constituir em uma das principais queixas dos docentes, ao gerar prejuízos ao processo de ensino-aprendizagem, constituindo-se em importante fator para explicar as oportunidades desiguais de aprendizado dos/as estudantes (Estrela, 1992; Silva \& Matos, 2017).

Em segundo lugar, quando se leva em consideração a comparação entre meninas e meninos, fica evidente que, conforme as percepções dos/as estudantes, os meninos ainda estariam protagonizando, com maior frequência, os comportamentos de indisciplina. Somente em um único caso, o de não realizar as atividades indicadas pelo/a professor/a, a porcentagem das respostas "frequentemente" e "sempre" somadas para as meninas foi superior à dos meninos: nesse caso, em apenas 1,4 pontos percentuais. As maiores diferenças encontradas entre meninas e meninos, quando consideradas em conjunto as opções "frequentemente" e "sempre", foram: distrair-se com objetos (17 pontos), fazer gozações ou brincadeiras com os/as colegas (23,1 pontos), desobedecer às ordens do/a professor/a (18,3 pontos), sair de sala sem permissão (16,2 pontos) e responder de forma mal-educada ou retrucar o/a professor/a ( 15 pontos). Assim, de modo geral, os dados parecem sugerir que as diferenças entre meninas e meninos tendem a aumentar à medida que os alvos da indisciplina passam a ser as relações interpessoais entre os sujeitos em sala de aula e, em especial, a autoridade do/a professor/a. Chamam a atenção, ainda, as diferenças relativas aos comportamentos de circular em sala de aula $(14,3 \%)$ e sair de sala sem a permissão do/a professor/a (16,2\%), que mostrariam que as meninas descumpririam com menor frequência as regras que definem os padrões de mobilidade em sala de aula. Uma hipótese plausível para explicar essas diferenças seria o modelo de socialização familiar de meninas e meninos: as meninas seriam geralmente educadas para ocupar o espaço privado, dos afazeres domésticos, para não circular sozin has na rua e não sair sem a permissão das famílias; os meninos, ao contrário, seriam estimulados a ocupar o espaço público, a circular pelas ruas. Cabe ainda destacar que, nessa pesquisa, não foram utilizados testes específicos para verificar se essas diferenças entre meninos e meninas foram estatisticamente significantes.

Desse modo, os dados do Q-PIV para os comportamentos de indisciplina escolar parecem corroborar diversos estudos que enfatizam o fato de as meninas se submeterem mais frequentemente à autoridade dos/as professores/as e se ajustarem melhor à disciplina da escola (Silva et al., 1999; Rodrigues, 2009). Em grande parte desses estudos, a maior adesão das meninas às regras escolares tende a ser explicada pelas características da socialização familiar, que exigiria delas a disciplina, o recato, a passividade e a submissão. Destaca-se, porém, que as diferenças entre meninas e meninos, de acordo com as percepções dos/as estudantes, foram quase sempre muito pequenas. Isso indica que, conforme Moreira e Santos (2002), Neves (2008) e 
Prodócimo et al. (2010), as meninas, mesmo que em proporções um pouco menores que os meninos, também transgridem as regras escolares. Ou seja, as meninas estariam agindo em desacordo com as expectativas sociais de gênero que esperariam delas um comportamento recatado, dócil e submisso na sociedade e na escola (Silva et al., 1999; Moreira \& Santos, 2002; Neves, 2008; Prodócimo et al., 2010).

\section{Autoclassificação e heteroclassificação}

Por meio dos dados do Q-HAE, tínhamos como objetivo identificar o modo como os/as estudantes tendem a perceber a si mesmos e os/as seus/suas colegas de sala de aula, tanto meninas quanto meninos, no que tange a frequência de suas participações nos episódios de indisciplina.

Desse modo, a Tabela 3 apresenta os resultados referentes à autoclassificação e à heteroclassificação realizadas pelos/as estudantes.

\section{TABELA 3}

Autoclassificação e heteroclassificação de meninas e meninos de acordo com a frequência de participação nos episódios de indisciplina $(n=167)$

\begin{tabular}{c|c|c|c|c}
\hline \multirow{2}{*}{ Classificação } & Gênero & $\begin{array}{c}\text { Frequente na disciplina } \\
(\%)\end{array}$ & $\begin{array}{c}\text { Frequente na } \\
\text { indisciplina (\%) }\end{array}$ & $\begin{array}{c}\text { Ocasional na } \\
\text { indisciplina (\%) }\end{array}$ \\
\hline \multirow{3}{*}{ Autoclassificação } & Geral & 40,8 & 5,9 & 53,3 \\
\cline { 2 - 5 } & Meninas & 50,0 & 1,4 & 48,6 \\
\cline { 2 - 5 } & Meninos & 30,2 & 11,1 & 58,7 \\
\hline \multirow{3}{*}{ Heteroclassificação } & Geral & 46,7 & 9,6 & 43,7 \\
\cline { 2 - 5 } & Meninas & 62,8 & 2,6 & 34,6 \\
\cline { 2 - 5 } & Meninos & 30,4 & 15,9 & 53,6 \\
\hline
\end{tabular}

Fonte: Elaboração dos autores a partir dos dados do Q-HAE.

Algumas conclusões gerais podem ser retiradas a partir da análise das heteroclassificações e autoclassificações dos/as estudantes no que tange às suas condutas em sala de aula.

Primeiramente, verificamos que, segundo as percepções dos/as estudantes, o comportamento de meninas e meninos diante das regras escolares não está pautado nos extremos, ou seja, no binômio disciplinado/indisciplinado. Destaca-se que apenas um percentual muito pequeno de estudantes foi autoclassificado e heteroclassificado como "frequentes na indisciplina": 5,9 e 9,6\%, respectivamente. No outro extremo, uma parcela significativa de estudantes foi autoclassificada e heteroclassificada como "frequentes na disciplina”: 40,8 e 46,7\%, respectivamente. Contudo, conforme alerta Silva (2007), embora seja comum querer enquadrar as condutas dos estudantes em polos extremados, no contexto escolar concreto, o que se verifica é a existência de uma multiplicidade de formas de condutas desses/as estudantes diante das regras escolares. Prova disso é o alto percentual de estudantes autoclassificado e heteroclassificado como "ocasionais na indisciplina": 53,3 e 43,7\%, respectivamente. Ou seja, isso indica que a maior parte dos/as estudantes só se envolveria em atos de indisciplina esporadicamente, provavelmente a depender de certas características da ação pedagógica do/a professor/a ou de situações específicas ocorridas durante a aula (Kounin, 1977; Estrela, 1992; Amado, 2001; Silva, 2007). Silva (2007) adverte que os/as estudantes "ocasionais na indisciplina" são normalmente negligenciados/as nas pesquisas educacionais por não se situarem nos dois extremos dos julgamentos escolares, em que pese sua relevância para se compreenderem os processos interativos que ocorrem em sala de aula. 
Em segundo lugar, os dados do Q-HAE confirmam os resultados encontrados no Q-PIV ao indicarem que, na percepção dos/as estudantes, as meninas se envolveriam menos em episódios de indisciplina, aderindo mais frequentemente às regras escolares (Silva et al., 1999; Rodrigues, 2009). Como indicam os dados de heteroclassificação, as meninas foram mais comumente percebidas como "frequentes na disciplina": 62,8 contra $30,4 \%$ dos meninos. Novamente, uma das hipóteses possíveis para explicar esses dados é que a socialização das meninas, especialmente no meio familiar, espera e desenvolve nelas, mais do que nos meninos, condutas de recato, docilidade e submissão às regras, mais do que se espera dos meninos.

Entretanto, nossos dados também indicam que existem muitas meninas que escapam a essa norma, transgredindo as expectativas sociais de gênero. Destaca-se que um pequeno percentual de meninas foi classificado como "frequentes na indisciplina" (9,6\%), sinalizando que, na percepção dos/as estudantes, algumas meninas teriam como conduta regular a transgressão das regras escolares. Ademais, a maior parte das estudantes foi heteroclassificada e autoclassificada como "ocasionais na indisciplina”, 43,7 e 53,3\%, respectivamente, sinalizando que não se furtariam a questionar as regras escolares, mesmo que de forma esporádica. Desse modo, é um equívoco pensar que as condutas das meninas na escola seguiriam um padrão rígido pautado apenas nas expectativas sociais de gênero, uma vez que verificamos uma multiplicidade de atitudes das meninas diante das regras escolares.

Do mesmo modo, destacamos a existência de um grupo importante de meninos classificado como "frequentes na disciplina" (30,4\%), o que demonstra que os garotos articulam algum tipo de afirmação das suas masculinidades com um comportamento escolar bastante positivo. Isso indica que é necessário compreender os múltiplos conceitos de masculinidade que circulam entre os estudantes.

Por fim, uma questão relevante a ser analisada é em que medida a heteroclassificação e a autoclassificação dos/as estudantes tendem a coincidir. Ou seja, em que medida a forma como os estudantes se percebem e são percebidos pelo conjunto de seus colegas se aproxima ou coincide? De modo geral, verificamos que $72,4 \%$ das classificações coincidiram e $27,6 \%$ divergiram. Ou seja, as percepções que os/as estudantes têm de si mesmos coincidem, em grande medida, com as percepções que o conjunto de seus/suas colegas tem delas ou deles. Esses dados parecem confirmar os estudos de Sortkaer e Reimer (2016), que constataram uma alta confiabilidade e consistência das percepções dos/as estudantes para avaliar situações de sala de aula.

Aprofundando as análises: o que dizem as entrevistas? Para aprofundar as análises, por meio das entrevistas, perguntamos aos/às estudantes sobre como percebiam possíveis diferenças e semelhanças nos comportamentos de meninas e meninos em sala de aula e sobre quais fatores explicariam essas diferenças e semelhanças.

A ampla maioria dos/as entrevistados/as afirmou categoricamente que percebiam muitas diferenças no comportamento de meninas e meninos.

Maria:? Não vejo semelhanças. Meninos e meninas não tem nada a ver! [risos]. Vejo diferenças demais! Totalmente. Conversa em aula, os meninos falam só com os meninos... diferença de agir, tipo, eles conversa mais com meninos, e as meninas conversa mais com todo mundo. $O$ jeito de falar, os meninos fala muito palavrão, e as meninas é mais delicada... acho que é isso.

Sthefane: Meninos. Eles são bagunceiros [risos].

Pedro: Os meninos. Porque somos mais despreocupados e brincamos mais. Esquecemos que estamos na sala de aula. 
Douglas: Os meninos, porque as meninas da minha sala são praticamente todas inteligentes $e$ ficam só caladas, e os meninos ficam andando, conversando.

De modo geral, os/as estudantes destacaram que as meninas eram delicadas, quietas, faziam as atividades, ficavam em casa, eram maduras e defendiam seus pontos de vista, enquanto os meninos falavam palavrão, eram agitados, folgados, brincavam na rua, não faziam atividades e eram infantis. Nesse sentido, durante as entrevistas, as percepções dos/as estudantes seguiram a mesma tendência já demonstrada na parte quantitativa deste estudo, de visualizar os meninos como mais indisciplinados.

Vale destacar que, para explicar essas diferenças entre meninas e meninos, os/as estudantes se pautaram fundamentalmente nas expectativas sociais de gênero, que tendem a atribuir a cada gênero comportamentos sociais específicos. Para isso, como mostra o depoimento de Maria, recorreram especialmente à socialização familiar como forma de explicar como esses comportamentos são construídos no seio das famílias.

Maria: Eu acho que pode ser influenciado pelos pais também, por exemplo, a minha mãe, ela não deixa a gente sair pra rua, se a mãe de outra menina deixa sair pra rua, jogar futebol, de brincar na rua de pega-pega, minha mãe não ia deixar eu fazer isso, então... não brinco muito com essas coisa, não. A influência da familia é muita, e a escola, um pouco. Acho que pelo convivio que eles têm com o futebol. Futebol é muito palavrão, essas coisa assim, gírias, menina não é muito dessas coisa, então acho que isso influencia bastante também. Eu acho que, dos dois, é mais as conversa mesmo. E, dos meninos, é mais essas briguinhas mesmo, brincando... menina é mais calma, mais conversa no cantinho delas, é isso.

É que para os/as entrevistados, meninas e meninos receberiam estímulos diferenciados, de forma que as meninas seriam desde cedo impelidas a desempenhar na sociedade papéis diferentes daqueles que deveriam ser desempenhados pelos meninos.

De fato, como vimos, muitos/as autores/as têm enfatizado que as expectativas de gênero baseadas na norma social heteronormativa são construídas socialmente e imprimem, desde a mais tenra idade, por meio da socialização familiar, as diferenciações de gênero. Conforme Quaresma (2010), essas diferenciações de gênero assumem um caráter hierarquizante, valorizam assimetricamente mulheres e homens, delegando ao gênero masculino atributos como a dominância e a instrumentalidade e ao gênero feminino características como a submissão e a expressividade. $\mathrm{Na}$ infância, logo desde o nascimento, os brinquedos e as brincadeiras emitem mensagens de gênero: as meninas ganham miniaturas de utensílios domésticos e bonecas, numa preparação para as funções domésticas e maternas, e os meninos ganham jogos de construção, bolas, carrinhos e armas, incentivando destrezas competitivas, agressivas e inventivas (Quaresma, 2010). Por meio dos brinquedos, podemos perceber a demarcação dos espaços (para as meninas, o espaço privado, doméstico, e, para os meninos, o espaço público), da agressividade (para os meninos, armas) e a divisão laboral (as meninas destinadas às atividades que remetem ao cuidado, à docência e à assistência, e os meninos destinados às atividades de construção, à carreira militar).

Dessa forma, as expectativas sociais de gênero que predominam em nossa sociedade parecem fortemente marcadas pelas diferenciações em que, das meninas, se espera o recato, a responsabilidade, a organização, a docilidade e o cuidado, e, dos meninos, espera-se certa agressividade, autonomia, exploração do espaço público e independência.

Contudo, as entrevistas realizadas com os/as estudantes revelam, também, que existem meninas e meninos que buscam romper com essas expectativas. Por exemplo, durante as entrevistas, alguns alunos evidenciaram a existência de meninas que se posicionam e que se fazem visíveis pela defesa de suas opiniões, rompendo com as expectativas sociais de gênero pautadas no recato e na submissão. 
Flávia: As meninas indisciplinadas estão tendo os mesmos comportamentos que os meninos indisciplinados, já as meninas disciplinadas têm o mesmo comportamento que os meninos disciplinados.

Flora: Vale mais para as meninas, porque as meninas hoje querem ser mais fodas, que ninguém mexe com elas, pra elas se sentirem superior. São os meninos e algumas meninas, as meninas são mais aparecidas. As meninas estão mais aparecidas, querendo ser famosinhas na escola. Por isso, elas fazem intriga e confusão. Os meninos são agitados, e as meninas, mais briguentas.

Eduardo: As meninas. Por exemplo, todos os dias quando eu chego, todo mundo chega atrasado depois do sinal, e na maioria das vezes são meninas, e quando o professor chama à atenção, a maioria é das meninas também.

$\mathrm{Na}$ percepção de Flora e Eduardo, as meninas têm demonstrado certa necessidade de se fazerem visíveis por meio de comportamento de indisciplina e de violência, algo similar ao que foi encontrado por Vargas (2008) e Neves (2008) em suas pesquisas. Dessa forma, podemos inferir que, para as meninas consideradas "indisciplinadas" ou "violentas", transgredir as expectativas sociais de gênero pode proporcionar poder e prestígio ante seus pares.

É preciso destacar, porém, que, conforme ilustra o depoimento de Sol, esse tipo de conduta pode ser percebido, também, como uma qualidade negativa das meninas.

Sol: Pra mim são as roupas. As roupas que algumas meninas usam, eu acho um absurdo. Por exemplo, dobrar o short ou tentar atrair a atração masculina dos meninos, porque eles já são homens, as meninas têm seios, corpo... essa atração que elas querem não é saudável pra um ambiente de escola, porque aqui é um ambiente de estudo. Não estou dizendo que a gente deve ser robô de prova ou robô de escola, divertir, sim... Algumas atitudes delas me incomoda como dobrar o short, subir a calça, levantar a blusa, porque, se você quer ser sensual, você tem que saber a hora e o momento, e, pra mim, se você quer ser sensual, você tem que ser com elegância. Pra você não ser intitulada de vadia, piranha ou puta, digamos assim. Eu admiro as mulheres mais velhas do que eu, que sabem se vestir, ter a sua sensualidade...

Como se vê, os desvios das meninas que transgridem os padrões de feminilidade estabelecidos podem ser alvo de uma avaliação negativa no ambiente escolar. Como no trabalho de Moreira e Santos (2002), a questão da sexualidade ganha centralidade nessas avaliações, uma vez que as meninas são vistas como sedutoras e provocadoras, discurso que acaba por exigir que elas tenham um comportamento assexuado no interior da escola. Essas garotas parecem, assim, alvo de uma dupla avaliação: como alunas e como mulheres. Desse modo, ante seus pares, parecem cometer um duplo desvio, na medida em que transgrediriam, ao mesmo tempo, as regras escolares e as regras sociais que definem as condutas esperadas das mulheres em nossa sociedade.

\section{Considerações finais}

Em que pesem seu impacto e recorrência no ambiente escolar, a indisciplina ainda tem pouca visibilidade nos estudos acadêmicos, raramente constituindo num objeto específico de análise. Ainda menos explorada academicamente tem sido a relação entre a indisciplina e a questão do gênero e/ou sexo dos/as estudantes, especialmente a indisciplina praticada pelas meninas nas escolas. Nesse sentido, consideramos que este trabalho tenha contribuído para minimizar uma importante lacuna no campo acadêmico e confirmado a relevância e potencialidade de se investigar a relação entre indisciplina e gênero. 
À guisa de conclusões, destacamos, como o resultado mais relevante deste trabalho, ter identificado que é um equívoco pensar que as condutas de meninas e meninos na escola seguem um padrão rígido pautado apenas nas expectativas sociais de gênero, uma vez que verificamos uma multiplicidade de atitudes de meninas e meninos diante das regras escolares.

Assim, embora, segundo a percepção dos/as estudantes, os meninos continuem a ser os maiores protagonistas dos comportamentos de indisciplina em sala de aula, as diferenças entre eles e as meninas não foram tão significativas para a maior parte dos comportamentos analisados. Conforme demonstraram Moreira e Santos (2002), Vargas (2008), Neves (2008) e Prodócimo et al. (2010), as meninas também transgridem as regras escolares, mesmo que, conforme mostramos, em proporções menores que os meninos. Isso significa que, em alguma medida, as meninas estariam agindo em desacordo com as expectativas sociais de gênero que esperariam delas um comportamento recatado, dócil e submisso na sociedade e na escola. Vale salientar, porém, que, conforme os depoimentos de alguns/as estudantes, as meninas que transgridem as expectativas sociais de gênero podem ser alvo de avaliações negativas por parte de seus/suas colegas. Esse fato nos levou a aventar a hipótese da existência do fenômeno da dupla desviança na escola investigada, uma vez que, para os expectadores/as, essas meninas transgridem, ao mesmo tempo, as regras escolares e os papéis sociais de gênero a elas endereçados (Matos \& Machado, 2012).

Por fim, salientamos que este estudo apresenta algumas limitações. Primeiramente, indicamos que a pesquisa se refere a um número restrito de estudantes, o que impede que se faça qualquer tipo de generalização dos seus resultados. Nesse sentido, seria relevante a construção de investigações que envolvessem um número maior de sujeitos de modo a permitir comparações mais amplas entre escolas e estudantes com perfis socioculturais diferenciados. Parece-nos que os instrumentos construídos e adaptados pela presente investigação se prestariam bem a essa finalidade. Ademais, tivemos dificuldade em trabalhar a interseccionalidade entre indisciplina e variáveis como cor/raça, religião e classe social, especialmente devido ao número reduzido de estudantes participantes da pesquisa, o que demandaria o emprego de técnicas estatísticas para, por exemplo, comparar e testar diferenças e relações entre variáveis. Nas próximas etapas da pesquisa, aprofundaremos nossas análises por meio da utilização de técnicas estatísticas mais sofisticadas, como o uso da análise fatorial para verificar as propriedades psicométricas dos instrumentos. Esses são alguns dos desafios que podem ser colocados a esse importante campo de estudos.

\section{Referências}

Amado, J. S. (2001). Interação pedagógica e indisciplina na aula. Edições Asa.

Aquino, J. G. (2016). Indisciplina escolar: Um itinerário de um tema/problema de pesquisa. Cadernos de Pesquisa, 46(161), 664-692. https://www.scielo.br/j/cp/a/wXBYFtgdsnsRMxPfMSWDBXC/ abstract/?lang=pt

Bardin, L. (2011). Análise de conteúdo. Edições 70.

Brito, R. S. (2004). Significados de gênero do fracasso escolar: Quando os modelos polares de sexo não são suficientes. [Dissertação de mestrado não publicada]. Faculdade de Educação da Universidade de São Paulo.

Brito, R. S. (2008). Fracasso de meninos no ensino fundamental: As contribuições da categoria de gênero na compreensão desse quadro. In M. P. Carvalho, \& R. P. Pinto (Orgs.), Mulheres e desigualdades de gênero (pp. 149-168). Fundação Carlos Chagas.

Bruggemann, O. M., \& Parpinelli, M. A. (2008). Utilizando as abordagens quantitativa e qualitativa na produção do conhecimento. Revista da Escola de Enfermagem da USP, 42(3), 563-568.

Carvalho, M. P. (2001). Mau aluno, boa aluna? Como as professoras avaliam meninos e meninas.

Revista Estudos Feministas, 9(2), 554-574. 
Carvalho, M. P. (2003). Sucesso e fracasso: Uma questão de gênero. Educação e Pesquisa, 29(1), 185-193.

Carvalho, M. P. (2004a). O fracasso escolar de meninos e meninas: Articulações entre gênero e cor/raça. Cadernos Pagu, 22, 247-290.

Carvalho, M. P. (2004b). Quem são os meninos que fracassam na escola? Cadernos de Pesquisa, 34(121), 11-40.

Carvalho, M. P. (2007). Desempenho escolar, gênero e raça: Desafios teóricos de uma pesquisa. In L. Paixão, $\&$ N. Zago. Sociologia da educação: Pesquisa e realidade brasileira (pp. 182-202). Vozes.

Carvalho, M. P. (2012). Teses e dissertações sobre gênero e desempenho escolar no Brasil (1993-2007):

Um estado da arte. Pro-Posições, 23(1), 147-162.

Dubet, F. (2011). Mutações cruzadas: A cidadania e a escola. Revista Brasileira de Educação, 16(47), 289-305.

Estrela, M. T. (1992). Relação pedagógica, disciplina e indisciplina na aula (Ciências da Educação). Porto Editora.

Koon, D. S. V. (2013). Exclusionary school discipline: An issue brief and review of the literature. University of California.

Kounin, J. S. (1997). Discipline and group management in classrooms. Holt, Rine-Hart \& Winston.

Matos, D. A. S. (2006). A percep̧̧ão dos alunos do comportamento comunicativo do professor de ciências [Dissertação de mestrado]. Universidade Federal de Minas Gerais.

Matos, R., \& Machado, C. (2012). Criminalidade feminina e construção do gênero: Emergência e consolidação das perspectivas feministas na criminologia. Análise Psicológica, 30(1-2), 33-47.

Mattos, C. L. G., \& Vasconcelos, S. S. (2015). A questão de gênero associada à (in)disciplina, uma combinação de risco? Um estudo de caso etnográfico. In Anais do IV Colóquio Internacional Educação, Cidadania e Exclusão: Didática e Avaliação (pp. 1-14). Universidade do Estado do Rio de Janeiro.

Moreira, M. F. S., \& Santos, L. P. (2002). Indisciplina na escola: Uma questão de gênero? Educação em Revista, (3), 141-160.

Morris, E. W., \& Perry, B. L. (2017). Girls behaving badly? Race, gender, and subjective evolution in the discipline of African American girls. Sociology Education, 20(5), 127-148.

Neves, P. R. C. (2008). As meninas de agora estão piores do que os meninos: Gênero, conflito e violência na escola [Dissertação de mestrado]. Universidade de São Paulo.

Organisation for Economic Co-Operation and Development. (2014). Talis 2013 results: An international perspective on teaching and learning. https://www.oecd.org/education/school/talis-2013-results.htm

Organização para a Cooperação e Desenvolvimento Econômico. (2011). A disciplina nas escolas está deteriorada? (Pisa em Foco, 4). https://download.inep.gov.br/acoes_internacionais/pisa/pisa_em_ foco/2011/pisa_em_foco_n4.pdf

Organização para a Cooperação e Desenvolvimento Econômico. (2013). Os estudantes alcançam melhores desempenhos nas escolas em que há disciplina em sala de aula? (Pisa em Foco, 32). https://www.oecd.org/pisa/pisaproducts/pisainfocus/PISA-EM-FOCO-N\%C2\%B032.pdf

Pasquali, L. (1999). Instrumentos psicológicos: Manual prático de elaboração. Laboratório de Pesquisa em Avaliação e Medida. Universidade de Brasília.

Prodócimo, E., Silva, R. G. C., Miguel, R. S., \& Recco, K. V. (2010). Meninas também agridem? Estudo sobre agressão entre escolares. Educação em Foco, 15(1), 59-76.

Quaresma, L. (2010). Violência escolar e de gênero: Vivências e representações sociais discentes. Sociologia: Revista do Departamento de Sociologia da FLUP, 20, 351-374.

Rodrigues, C. A. G. (2009). Representação social de gênero no fracasso escolar de meninos [Dissertação de mestrado]. Universidade Estácio de Sá.

Santos, L. P. (2007). Garotas indisciplinadas numa escola de ensino médio: Um estudo sob o enfoque de gênero [Dissertação de mestrado]. Universidade de São Paulo.

Scott, J. (1990). Gênero: Uma categoria útil para análise histórica. Tradução C. R. Dabat, \& M. B. Ávila. Educação \& Realidade, 2(16), 5-22. 
Silva, C. A. D., Barros, F., Halpern, S. C., \& Silva, L. A. D. (1999). Meninas bem-comportadas, boas alunas; meninos inteligentes, indisciplinados. Cadernos de Pesquisa, (107), 207-225.

Silva, L. C. (2007). Disciplina e indisciplina na aula: Uma perspectiva sociológica [Tese de doutorado]. Universidade Federal de Minas Gerais.

Silva, L. C., \& Matos, D. A. S. (2014). As percepções dos estudantes mineiros sobre a incidência de comportamentos de indisciplina em sala de aula: Um estudo baseado nos dados do SIMAVE/ PROEB 2007. Revista Brasileira de Educação, 19(58), 713-729.

Silva, L. C., \& Matos, D. A. S. (2016). Indisciplina e violência nas escolas da Região dos Inconfidentes: Diagnóstico e identificação de práticas docentes associadas à melhoria do ambiente de aprendizagem da sala de aula [Relatório Final da Pesquisa]. Fundação de Amparo à Pesquisa do Estado de Minas Gerais.

Silva, L. C., \& Matos, D. A. S. (2017). Indisciplina no PISA: Entre o intra e o extraescolar. Estudos em Avaliação Educacional, 28(68), 382-416.

Silva, L. C., \& Nogueira, M. A. (2008). Indisciplina ou violência na escola? Uma distinção possível e necessária. In L. A. O. Gonçalves, \& S. Tosta (Orgs.), A sindrome do medo contemporâneo e a violência escolar (pp. 15-62). Autêntica.

Sortkær, B., \& Reimer, D. (2016). Disciplinary climate and student achievement: Evidence from schools and classrooms [Working Paper]. Aarhus University.

Vargas, J. R. (2008). Meninas (mal)comportadas: Posturas e estranhamentos em uma escola pública de periferia [Dissertação de mestrado]. Universidade Federal do Rio Grande do Sul.

\section{Nota sobre autoria}

Os autores participaram de todas as etapas de concepção e redação do artigo.

\section{Disponibilidade de dados}

Os dados referentes às entrevistas realizadas para a pesquisa e questionários aplicados aos alunos estão protegidos por questões éticas. Mas podem ser disponibilizados, desde que solicitados e adotados os procedimentos de preservação das identidades dos sujeitos.

\section{Como citar este artigo}

Silva, L. C. da, \& Pereira, E. A. dos S. (2022). Percepções sobre o comportamento de indisciplina de meninas e meninos na escola. Cadernos de Pesquisa, 52, Artigo e07446. https://doi.org/10.1590/198053147446 